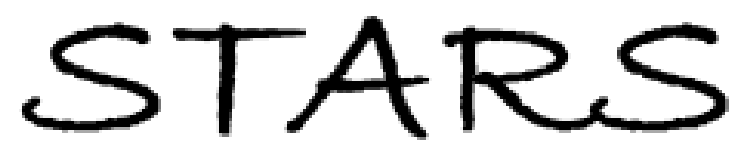

University of Central Florida

STARS

$1-1-2009$

\title{
Diameter dependent strength of carbon nanotube reinforced composite
}

\author{
Ying Sun \\ University of Central Florida \\ Quanfang Chen \\ University of Central Florida
}

Find similar works at: https://stars.library.ucf.edu/facultybib2000 University of Central Florida Libraries http://library.ucf.edu

This Article is brought to you for free and open access by the Faculty Bibliography at STARS. It has been accepted for inclusion in Faculty Bibliography 2000 s by an authorized administrator of STARS. For more information, please contactSTARS@ucf.edu.

\section{Recommended Citation}

Sun, Ying and Chen, Quanfang, "Diameter dependent strength of carbon nanotube reinforced composite" (2009). Faculty Bibliography 2000s. 2206.

https://stars.library.ucf.edu/facultybib2000/2206

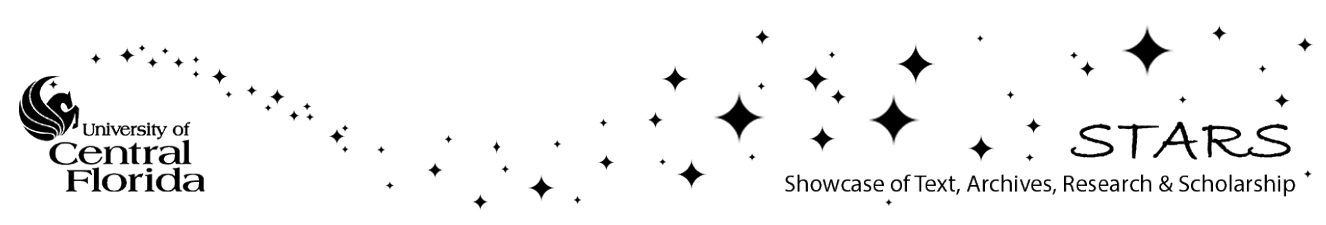




\section{Diameter dependent strength of carbon nanotube reinforced composite}

Cite as: Appl. Phys. Lett. 95, 021901 (2009); https://doi.org/10.1063/1.3168520

Submitted: 07 March 2009 . Accepted: 11 June 2009. Published Online: 14 July 2009

Ying Sun, and Quanfang Chen

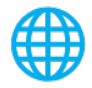

\section{ARTICLES YOU MAY BE INTERESTED IN}

Strong and ductile nanostructured Cu-carbon nanotube composite

Applied Physics Letters 95, 071907 (2009); https://doi.org/10.1063/1.3211921

Grain refinement assisted strengthening of carbon nanotube reinforced copper matrix nanocomposites

Applied Physics Letters 92, 121901 (2008); https://doi.org/10.1063/1.2899939

First-principles study of interfacial interaction between carbon nanotube and $\mathrm{Al}_{2} \mathrm{O}_{3}(0001)$ Journal of Applied Physics 121, 025304 (2017); https://doi.org/10.1063/1.4973741

\section{Applied Physics Letters}

Mid-IR and THz frequency combs special collection

Read Now! 


\title{
Diameter dependent strength of carbon nanotube reinforced composite
}

\author{
Ying Sun and Quanfang Chen ${ }^{\text {a) }}$ \\ Department of Mechanical, Materials, and Aerospace Engineering, MEMS and Nanomaterials Lab, \\ University of Central Florida, Orlando, Florida 32816-2450, USA
}

(Received 7 March 2009; accepted 11 June 2009; published online 14 July 2009)

\begin{abstract}
Experimental results of carbon nanotube $(\mathrm{CNT})$ reinforced copper composites $(\mathrm{Cu} / \mathrm{CNT})$ have shown that the resultant tensile strength of $\mathrm{Cu} / \mathrm{CNT}$ composite is CNT diameter dependent, in a form of parabolic relationship that the smaller the CNT diameters the greater the resultant strength of the $\mathrm{Cu} / \mathrm{CNT}$ composites. The largely increased strength of $\mathrm{Cu} / \mathrm{CNT}$ composited is attributed to the good CNT dispersion in both the electrolyte and in composite after electrochemical deposition, as well as to the good interfacial bonding formed by the electrochemical deposition process. Smaller CNT diameters result in greater total interfacial bonding area thus the greater resultant strength of the composite. (C) 2009 American Institute of Physics. [DOI: 10.1063/1.3168520]
\end{abstract}

Carbon nanofibers (NFs) such as carbon nanotubes (CNTs), including single walled CNT and multiwalled CNT (MWCNT), are fibers with diameters range from 1 to about $100 \mathrm{~nm}$ and a large aspect ratio $(>1000)$. CNTs have been regarded as the stiffest and strongest material ever developed, mainly owing to their perfect atomic arrangement and intrinsic strong in-plane $s p^{2}-s p^{2}$ covalent bonds between carbon atoms. ${ }^{1-9}$ For example, the Young's modulus is about $1.0-1.8 \mathrm{TPa}$ and the ultimate tensile strength is about $30-200$ $\mathrm{GPa}$, together with an elongation at break of about $10 \%-30 \% .^{2-8}$ In addition, CNTs are chemically stable and have remarkable properties in electrical and thermal conduction. ${ }^{9}$ All these attributes make CNTs ideal candidates as reinforcement fillers to develop advanced nanocomposites. So far various efforts have been made to develop nanotube/NF reinforced composites with different matrices. For example, many studies have been done to develop polymer based composites by using PMMA ${ }^{10,11}$ and epoxy resins, ${ }^{12-14}$ in addition to CNTs reinforced ceramic composites ${ }^{15,16}$ and metallic composites. ${ }^{17-19}$ Although CNTs with different diameters are used in these composites, no results have been reported about CNT diameter effects on the resultant strength of composites. Therefore, it is important to understand issues regarding CNTs' diameter on resultant strength of composites. In this article, CNTs with different diameters were added into copper matrix to form $\mathrm{CNT} / \mathrm{Cu}$ nanocomposites by electrochemical codeposition developed by authors' group. ${ }^{20-22}$ Resultant tensile strength was mea-

TABLE I. CNTs used in the experiments.

\begin{tabular}{lccc}
\hline \hline & OD & Length & Source \\
\hline DWNT & $1.5-3.0 \mathrm{~nm}$ & $\sim 2 \mu \mathrm{m}$ & Carbon Nanotechnologies Inc. \\
MWNT & $<8 \mathrm{~nm}$ & $10-30 \mu \mathrm{m}$ & Cheap Tubes Inc. \\
MWNT & $8-15 \mathrm{~nm}$ & $10-50 \mu \mathrm{m}$ & Cheap Tubes Inc. \\
MWNT & $20-30 \mathrm{~nm}$ & $10-30 \mu \mathrm{m}$ & Cheap Tubes Inc. \\
MWNT & $30-50 \mathrm{~nm}$ & $10-20 \mu \mathrm{m}$ & Cheap Tubes Inc. \\
\hline \hline
\end{tabular}

\footnotetext{
a) Author to whom correspondence should be addressed. Electronic mail: qchen@mail.ucf.edu.
}

sured, which shows good relationship between CNT diameter and the resultant strength.

Purified MWCNTs were obtained commercially and CNTs with different diameters are shown as in Table I. Figure 1 shows transmission electron microscopy (TEM) images of MWCNTs that verify the diameter range and the length. The surface morphology of these nanotubes shows some damages on the outmost layer but there are no obvious differences among them. The received CNTs were treated similarly as ${ }^{20-22}$ shown in Table II. Same amount $(150 \mathrm{mg} / \mathrm{l})$ of different CNTs was added to the copper electrolyte for comparison purpose. Pulse-reverse electrochemical deposition was carried out by using square pulse waveforms. A forward (deposition) of $5 \mathrm{~ms}$ and then a reverse time of $1 \mathrm{~ms}$ was applied for trimming purpose. A peak current density of $20 \mathrm{~mA} / \mathrm{cm}^{2}$ was chosen for both forward and reverse waveform. For comparison purposes, pure copper was deposited under the same condition.

Dog-bone shaped microsamples were prepared by using the standard UV-LIGA process, as shown in Fig. 2. SU-8 (MicroChem Inc.) was used for fabricating micromolds for the test samples. After evaporating a thin layer of copper onto a silicon wafer as the seed layer, SU-8 molds were fabricated on the wafer substrate by photolithography. The thickness of SU-8 molds was controlled at about $50 \mu \mathrm{m}$. The codeposition of copper and CNTs were realized into SU-8 molds by using the pulse-reverse electrochemical deposition in the electrolyte bath (Table II). After deposition, SU-8 molds were removed by using SU-8 remover and test samples were received after separating from the substrate.

The samples used in the present study were about $40 \mu \mathrm{m}$ thick and $400 \mu \mathrm{m}$ in width and the gauge (L, Fig. 2) is $4 \mathrm{~mm}$. The sample's actual thickness was determined by using scanning electron microscopy (SEM). Uniaxial tensile

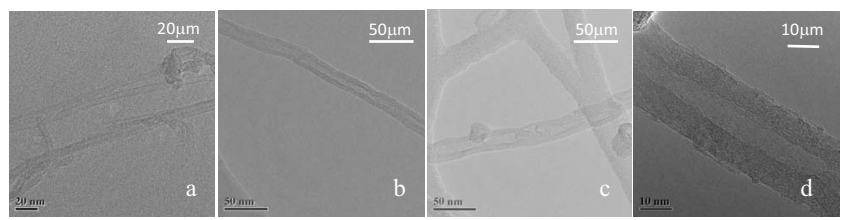

FIG. 1. TEM results of MWNTs (a) CNT $<8 \mathrm{~nm}$, (b) CNT $8-15 \mathrm{~nm}$, (c) CNT 20-30 nm, and (d) CNT 30-50 nm. 
TABLE II. Composition of the electrolyte for electrochemical deposition.

\begin{tabular}{cccc}
\hline \hline Copper sulfate & Sulfuric acid (98\%) & Hydrochloric acid & CNTs \\
\hline $150 \mathrm{~g} / 1$ & $100 \mathrm{ml} / 1$ & $0.13 \mathrm{ml} / 1$ & $150 \mathrm{mg} / \mathrm{l}$ \\
\hline \hline
\end{tabular}

tests were performed on a MTS Tytron 250 Microforce Testing System and a force loading rate of $50 \mathrm{mN} / \mathrm{s}$ was used during the test. At least five samples of each group (pure $\mathrm{Cu}$ and $\mathrm{Cu} / \mathrm{CNT}$ composites with different diameters) were tested. After test, both SEM (JOEL 6400F) and TEM were used to study the as deposited and the fractured surface morphology as well as texture of samples.

Figure 3 shows SEM images of surface morphologies of the as-deposited pure copper [Fig. 3(a)] and Cu/CNTs composites [Figs. 3(b)-3(f)]. The surface morphology of the pure copper is smoother than that of the $\mathrm{Cu} / \mathrm{CNT}$ composites fabricated with different diameters. For $\mathrm{Cu} / \mathrm{CNT}$ composites, dispersed bulges can be seen on surfaces. It indicates that the addition of CNTs into copper introduces additional nucleation sites that cause the rougher surfaces. It shows also that when the outer diameters (ODs) of CNTs increases, the resultant surface roughness of $\mathrm{Cu} / \mathrm{CNT}$ composites increases too [Figs. 3(b)-3(f)].

Figure 4(a) shows typical results of tensile stress-strain responses of the fabricated pure $\mathrm{Cu}$ and $\mathrm{Cu} / \mathrm{CNT}$ composites with different CNT diameters. The ultimate strength of pure copper is about $230 \mathrm{MPa}$, which is the similar as published data. ${ }^{21}$ When CNTs with diameter of 30-50 nm was added to form $\mathrm{Cu} / \mathrm{CNT}$ composite, the resultant tensile strength is increased to about $350 \mathrm{MPa}$, or about $52 \%$ greater than that of pure copper in tensile strength. Under the same condition, if the same CNTs smaller diameters $(20-30 \mathrm{~nm})$ were used, the resultant tensile strength is increased to about $400 \mathrm{MPa}$, or about $74 \%$ greater than that of pure copper. When CNT diameter of $<8 \mathrm{~nm}$ was used, the resultant tensile strength is increased to about $500 \mathrm{MPa}$, or about $117 \%$ higher than that of pure copper. Similarly, if $\mathrm{Cu} / \mathrm{CNT}$ nanocomposite was fabricated with diameter of $1.5-3 \mathrm{~nm}$ the resultant tensile strength is increased to about $670 \mathrm{MPa}[\mathrm{Cu} / \mathrm{DWNT}$, Fig. 4(a)]. This value is about $191 \%$ greater than that of pure copper or almost about three times of that of the pure copper fabricated under the same condition. These data show that the smaller the CNT diameters, the greater tensile strength will be resulted [thicker line, Fig. 4(b)]. However, Cu/CNT composites with larger CNT diameters produce greater duc-

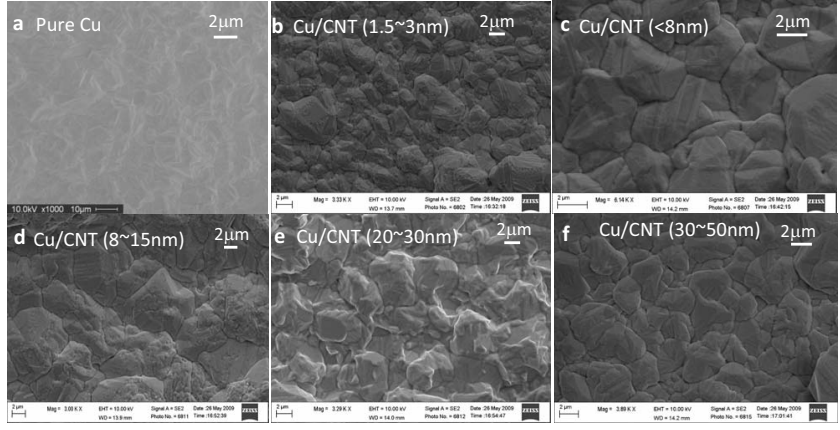

FIG. 3. SEM images of the (a) deposited pure copper and Cu/CNT composite samples (after using alcohol to reveal grain boundaries) with different CNT diameters: (b) CNT 1.5-3 nm, (c) CNT $<8$ nm, (d) CNT 8-15 nm, (e) CNT 20-30 nm, and (f) CNT 30-50 nm

tility than that of CNTs with smaller diameter (Fig. 4).

In order to understand if other effects such as grain size and density are issues to the resultant strength, during this study following characterizations were made. First, alcohol was used as etchant to reveal grain boundaries on the composites' surfaces (Fig. 3). SEM results show that the grain size of all composites are similar, in a range of $2-5 \mu \mathrm{m}$. This makes sense since copper's grain size is dependent on the deposition condition including the electrolyte composition, the deposition temperature, and the current density used for deposition. Since these conditions were all kept the same during the deposition of composites, the resultant grain size should be similar. For example, the grain size and of smallest CNT [1.5-3 nm, Fig. 3(b)] used and the largest CNT [Fig. 3(f)] used are similar but the resultant strengths are about two times different. Therefore, effects of grain size on the resultant strength among all composites tested are considered negligible. As for the density effects, since a deliberated purse-reverse deposition waveform was developed to trim the front surface that as Fig. 3 shows that the as deposited composites are dense. Therefore, no dependence of resultant strength on density can be identified.

SEM images of fractured morphologies are shown in Fig. 5. It indicates that for pure copper [Fig. 5(a)], the fractured surface is relatively flat. However, the fractured surface of $\mathrm{Cu} / \mathrm{CNT}$ composite [Fig. 5(b)] shows textured feature. A TEM images is shown in Fig. 5(c) that individual CNTs are clearly seen trapped in the copper matrix. Figure 5(c) shows that CNTs are well dispersed and are still trapped in the $\mathrm{Cu}$ matrix after the fracture test. No CNTs are pulled out from
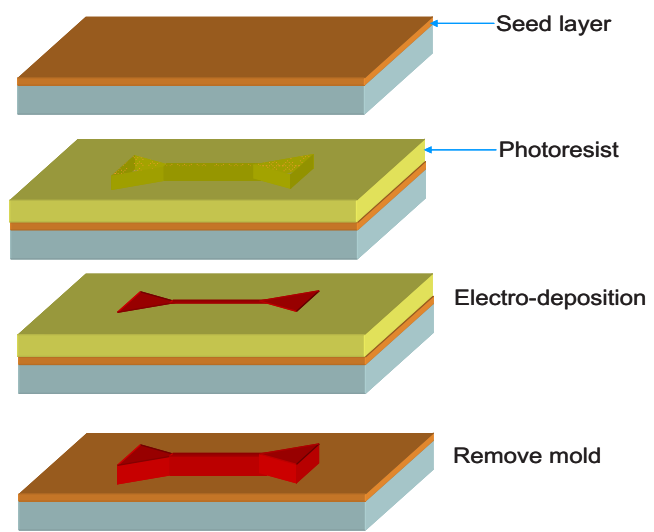

Remove mold

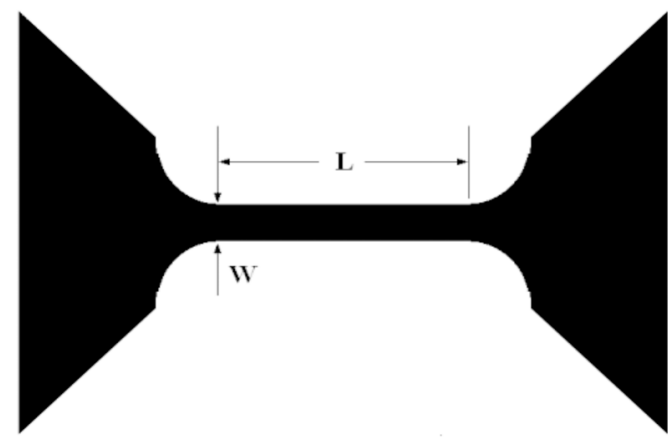

FIG. 2. (Color online) Schematic flow chart of LIGA process and the shape of the tensile test sample. 

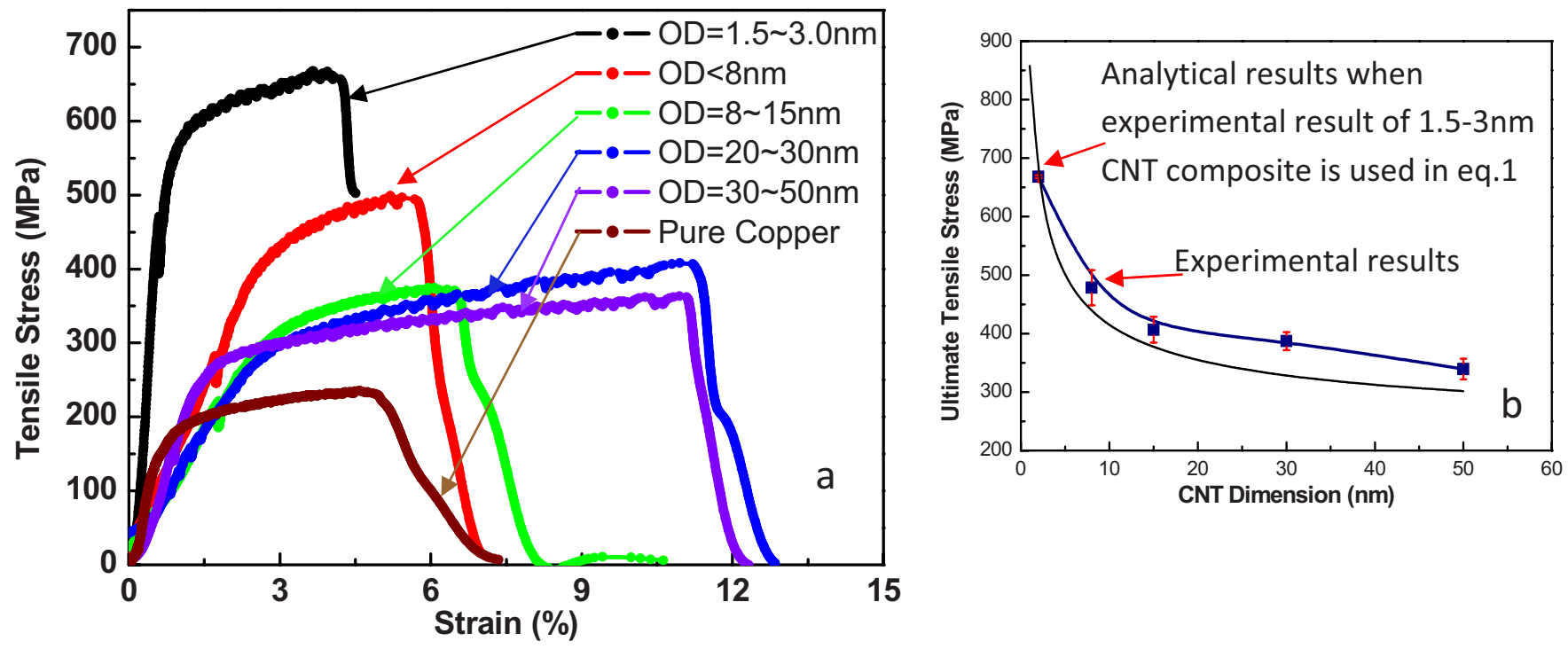

FIG. 4. (Color online) (a) Tensile stress-strain curve of pure $\mathrm{Cu}$ and $\mathrm{Cu} / \mathrm{CNT}$ composites with different diameters and (b) averaged tensile strengths versus CNT diameters of $\mathrm{Cu} / \mathrm{CNT}$ composites.

the $\mathrm{Cu}$. Therefore, good interfacial bonding between CNTs and copper is formed,

$$
\sigma^{2}=\frac{A}{d_{\mathrm{CNT}}},
$$

where $A$ is a constant. Experimental results of tensile strength versus CNT diameters [thicker line, Fig. 4(b)] show a parabolic relationship. If we assume this parabolic relationship as denoted in Eq. (1), where $\sigma$ is the tensile strength, $d_{\text {CNT }}$ stands for CNT's diameter, and $A$ is a constant that needs to be determined. If tensile strength data of $\mathrm{Cu} / \mathrm{CNT}$ with diameter of $1.5-3 \mathrm{~nm}$ is used in Eq. (1), the analytical results tensile strength of $\mathrm{Cu} / \mathrm{CNT}$ composites versus $\mathrm{CNT}$ diameters, as denoted in Eq. (1) can be plotted [thinner line, Fig. 4(b)]. Figure 4(b) indicates that the experimental results agree well $(<5 \%)$ with the predications made by Eq. (1). The parabolic relationship between the resultant strength and CNT diameters can be attributed to the interfaces between CNT and the matrix. Smaller CNTs result in large total interfacial bonding areas if CNTs are well dispersed in the matrix. Analytical results have shown that the resultant tensile strength of CNT reinforced nanocomposite has a parabolic relationship with the CNT diameter ${ }^{23}$ that is similar, as shown in the Fig. 4(b).

Results of CNT/Cu composites reported in this article have shown that the resultant tensile strength of $\mathrm{Cu} / \mathrm{CNT}$ composites is CNT diameter dependent. The smaller the

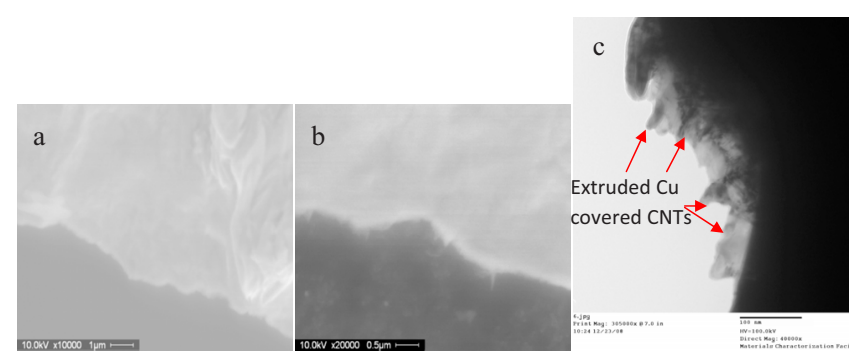

FIG. 5. (Color online) SEM images of fractured morphologies of (a) pure copper and (b) $\mathrm{Cu} / \mathrm{CNT}(20-30 \mathrm{~nm})$ composite. A TEM image of the fractured $\mathrm{Cu} / \mathrm{CNT}$ (c) shows trapped CNTs in $\mathrm{Cu}$ matrix.
CNT diameters, the greater the resultant strengths of $\mathrm{Cu} /$ CNT composites will result. A parabolic relationship between CNT diameters and the resultant tensile strength has been established, which has been verified by the experimental results. The tensile strength of $\mathrm{Cu} / \mathrm{CNT}$ composite is as high as $670 \mathrm{MPa}$, which is about three times greater of that of pure copper. The largely increased strength is attributed to the good CNT dispersion in the electrolyte and the good CNT dispersion in $\mathrm{Cu}$ after deposition as well as to the good interfacial bonding formed by the electrochemical deposition process.

${ }^{1}$ S. Iijima, Nature (London) 354, 56 (1991).

${ }^{2}$ A. V. Desai and M. A. Haque, Thin-Walled Struct. 43, 1787 (2005).

${ }^{3}$ K.-T. Lau and D. Hui, Composites, Part B 33, 263 (2002).

${ }^{4}$ N. M. Treacy, T. W. Ebbesen, and J. M. Gibson, Nature (London) 381, 678 (1996).

${ }^{5}$ E. W. Wong, P. E. Sheehan, and C. M. Lieber, Science 277, 1971 (1997).

${ }^{6}$ J. P. Salvetat-Delmotte and A. Rubio, Carbon 40, 1729 (2002).

${ }^{7}$ P. Poncharal, Z. L. Wang, D. Ugarte, and W. De, Science 283, 1513 (1999).

${ }^{8}$ D. Qian, G. J. Wagner, W. K. Liu, M. F. Yu, and R. S. Ruoff, Appl. Mech. Rev. 55, 495 (2002).

${ }^{9}$ H. Dai, Surf. Sci. 500, 218 (2002).

${ }^{10}$ R. Haggenmueller, H. Gommans, A. G. Rinzler, and J. E. Fischer, Chem. Phys. Lett. 330, 219 (2000).

${ }^{11}$ C. A. Cooper, D. Ravich, D. Lips, J. Mayer, and H. Wagner, Compos. Sci. Technol. 62, 1105 (2002).

${ }^{12}$ A. Allaoui, Compos. Sci. Technol. 62, 1993 (2002).

${ }^{13}$ K. T. Lau, Compos. Sci. Technol. 63, 1161 (2003).

${ }^{14}$ K. T. Lau and D. Huai, Carbon 40, 1605 (2002).

${ }^{15}$ X. T. Wang, N. P. Padture, and H. Tanaka, Nature Mater. 3, 539 (2004).

${ }^{16}$ G. D. Zhan, J. D. Kuntz, J. Wan, and A. K. Mukherjee, Nature Mater. 2, 38 (2003).

${ }^{17}$ C. L. Xu, B. W. Wei, R. Z. Ma, J. Liang, X. K. Ma, and D. H. Wu, Carbon 37, 855 (1999).

${ }^{18}$ X. Chen, J. Xia, J. Peng, W. Li, and S. Xie, Compos. Sci. Technol. 155, 274 (2002).

${ }^{19}$ T. Kuzumaki, O. Ujiie, H. Ichinose, and K. Ito, Adv. Eng. Mater. 2, 416 (2000).

${ }^{20}$ Y. Sun, J. Shen, M. Liu, and Q. Chen, Nanotechnology 18, 505704 (2007).

${ }^{21}$ G. Chai, Y. Sun, J. Sun, and Q. Chen, J. Micromech. Microeng. 18, 035013 (2008).

${ }^{22}$ Q. Chen, G. Chai, and B. Li, J. Nanoeng. Nanosyst. 219, 67 (2006).

${ }^{23} \mathrm{Q}$. Chen (unpublished). 